\title{
Lymphocytes from Enlarged Iliac Lymph Nodes as Fusion Partners for the Production of Monoclonal Antibodies after a Single Tail Base Immunization Attempt
}

\author{
Yoshikazu Sado $^{1}$, Satoko Inoue ${ }^{1}$, Yasuko Tomono ${ }^{1}$ and Hiroyuki Omori ${ }^{1}$

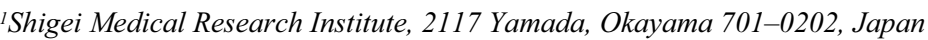

Received January 6, 2006; accepted April 3, 2006; published online April 26, 2006

\begin{abstract}
A novel method of preparing hybridomas producing mouse monoclonal antibodies was established, called "the mouse iliac lymph node method". Lymphocytes from enlarged iliac lymph nodes from mice injected intramuscularly at the tail base with an emulsion of antigen and Freund's adjuvant were used for cell fusion. For the most part, lymph node lymphocytes from two mice were used for a single cell fusion attempt. Ovalbumin was used as the antigen and the results of fusion were compared with the results of a previous report (Cell Struct. Funct. 20; 151-156, 1995). Approximately 100 positive wells producing antibody of interest were identified using this method. By comparison, approximately 10 positive wells were identified using the more conventional mouse spleen method after three immunization injections. The relative proportions of hybridomas producing IgM, IgG1, IgG2a, IgG2b, and IgG3, following fusion using iliac lymph node lymphocytes obtained 14 days after injection were $14.0 \%, 78.7 \%, 3.2 \%, 3.5 \%$ and $0.5 \%$, respectively. This method demonstrated the following advantages: (1) a single injection of the antigen emulsion was sufficient, (2) the lymph nodes were ready for use 14 days after injection, and (3) a high yield of positive hybridomas was obtained.
\end{abstract}

Key words: mouse monoclonal antibody, iliac lymph node, cell fusion, tail base immunization

\section{Introduction}

Since monoclonal antibodies were first produced in mice 30 years ago [7], mouse monoclonal antibodies have been produced using sensitized lymphocytes from the mouse spleen. The use of mouse lymph node lymphocytes for the production of mouse monoclonal antibodies has not been extensively examined $[2,3,8]$, however they can be used for cell fusion. The only limiting factor to date has been the small number of lymph node lymphocytes able to be obtained from a mouse, which is insufficient for cell fusion $[2,9]$.

In 1995, we described a novel method, known as the rat lymph node method, in which medial iliac lymph node lymphocytes from rats immunized with an antigen emulsion via the hind footpads are used as fusion partners for cell fusion [5]. This produces approximately 10 -fold the number

Correspondence to: Yoshikazu Sado, Ph.D., Shigei Medical Research Institute, 2117 Yamada, Okayama 701-0202, Japan.

E-mail: sado@shigei.or.jp of specific antibody-producing hybridomas than the more conventional method using mouse or rat splenic lymphocytes [5]. However, this method cannot be used in mice, since injection of an antigen emulsion into the hind footpads of mice does not result in sufficient enlargement of draining lymph nodes, such as the popliteal, inguinal, and iliac lymph nodes, to enable cell fusion.

Through trial and error, we discovered that intramuscular injection of the tail base with an antigen emulsion enlarges mouse iliac lymph nodes very effectively, and that lymph node lymphocytes from two immunized mice are sufficient for a single cell fusion attempt. The mouse method using lymphocytes from enlarged lymph nodes demonstrated similar characteristics to the rat lymph node method [5], with the following advantages: (1) one injection of antigen emulsion was sufficient, (2) the lymph nodes were ready for use two weeks after injection, and (3) a high yield of positive hybridomas was obtained. 


\section{Materials and Methods}

\section{Animal immunization}

Chicken ovalbumin (Grade VII, Sigma, St. Louis, MO, U.S.A.) and Freund's complete adjuvant (Difco Laboratories, Detroit, IL, U.S.A.) were used for making antigen emulsion. Freund's complete adjuvant $(0.6 \mathrm{ml})$ and 1.5 $\mathrm{mg} / \mathrm{ml}$ chicken ovalbumin solution $(0.3 \mathrm{ml})$ were emulsified in two 1-ml Luer-lock glass syringes with a double-ended locking needle connector. After emulsification was completed, one of the glass syringes containing the emulsion was disconnected from the locking connector and a $27 \mathrm{G} \times 3 / 4$ " needle attached.

Eight-week-old female mice were used. BALB/ cAnNCrlCrlj mice (BALB/c) were purchased from Charles River Laboratories Japan, Inc., Yokohama, while $\mathrm{C} 3 \mathrm{H} /$ $\mathrm{HeNJcl}$ mice $(\mathrm{C} 3 \mathrm{H} / \mathrm{He})$, and closed colony Jcl: ICR mice (ICR), were purchased from Clea Japan, Inc., Tokyo. Mice were anesthetized and injected intramuscularly at the right and left tail base with an emulsion $(0.1 \mathrm{ml}$ in total) containing $50 \mu \mathrm{g}$ chicken ovalbumin and Freund's complete adjuvant. Nine BALB/c mice were injected subcutaneously at the tail base with the same amount of antigen emulsion.

The mice were kept in polycarbonate plastic cages containing wood shavings for bedding. All animal experiments were conducted in accordance with the Guidelines for Laboratory Animal Experiments of the Shigei Medical Research Institute.

\section{Cell fusion}

A mouse myeloma cell line, SP2/0-Ag14 [10], was used for cell fusion. Mice were sacrificed 11, 14, 21, and 28 days after injection. Iliac lymph nodes were collected and lymph node lymphocytes from 2 mice were pooled and used for each cell fusion attempt. Cell number was determined using a blood corpuscle counting chamber after lymph nodes were passed through a 200-mesh stainless steel wire mesh. Cell fusion was performed according to the method of Kishiro et al. [5], after which the cells were cultured in four 96-well plates. On days 9 and 10 after cell fusion, culture supernatant was collected and assayed by solid-phase enzyme-linked immunosorbent assay (ELISA).

\section{Serum antibody titers and screening assay}

Mouse serum was collected at sacrifice and serum antibody titers against ovalbumin were determined by ELISA using the 2-fold dilution method [5].

Supernatant collected from the 96-well culture plates was screened for the production of anti-ovalbumin antibodies using ELISA, according to the method of Kishiro et al. [5]. Rabbit antibodies to mouse immunoglobulins (Dako A/S, Glostrup, Denmark), and sheep antibodies to mouse IgM, IgG1, IgG2a, IgG2b, and IgG3 (Nordic Immunological Laboratories, Tilburg, Netherlands), were used as peroxidase-conjugated secondary antibodies. Positive wells were defined as wells that showed an absorbance of 0.3 units or higher.

\section{Statistical analysis}

Statistical analyses were performed with the StatView program (Abacus Concepts, Berkeley, CA, USA) using Student's t-test. P values of less than 0.05 were considered statistically significant.

\section{Results}

\section{Enlarged mouse iliac lymph nodes}

Intramuscular tail base injection (Fig. 1) of an emulsion containing antigen and adjuvant induced hypertrophy of the iliac lymph nodes in the mice (Fig. 2a). Enlargement of both the right and left iliac nodes usually occurred, and a range of sizes was observed. Often, two iliac lymph nodes were present on either side of the caudal vena cava; however, sometimes three lymph nodes were present. They were spherical in shape and usually approximately 2 to $4 \mathrm{~mm}$ wide, 3 to $5 \mathrm{~mm}$ long, and contained anywhere from $1 \times 10^{7}$ to $2 \times 10^{7}$ cells per mouse after immunization (Fig. $2 \mathrm{~b}$ ). The injected antigen emulsion was always found in the muscles of the tail base, and often found in the sacral lymph nodes and within cysts in the peritoneal cavity.

To find and collect the iliac lymph nodes from agematched normal mice was more difficult than to find and collect the enlarged iliac lymph nodes of immunized mice, due to the small size of the nodes and their being buried under the retroperitoneal membrane in the normal mice. The iliac lymph nodes from the normal mice were spherical in shape, usually about $1 \mathrm{~mm}$ wide, 1 to $2 \mathrm{~mm}$ long, and contained anywhere from $1 \times 10^{6}$ to $2 \times 10^{6}$ cells per mouse (Fig. 2c).

Nine mice injected with antigen emulsion subcutaneously at the tail base were sacrificed 14 days after the injection to confirm the injection site effect. The inguinal lymph nodes were enlarged in all mice; however, the iliac lymph nodes remained normal in size in 7 of the 9 mice. In the 2 mice with the enlarged iliac lymph nodes, a portion of the emulsion was present in the muscle at the injection site.

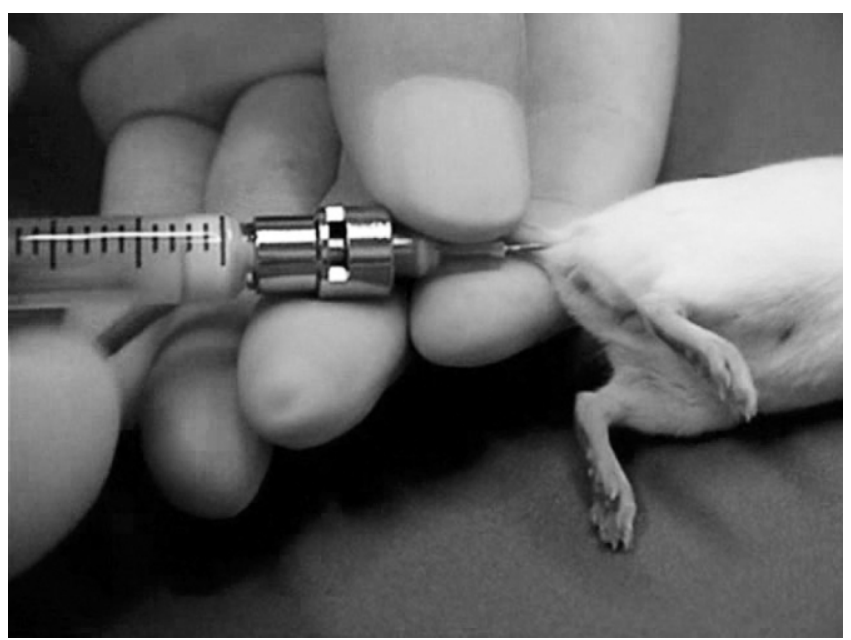

Fig. 1. Intramuscular injection of antigen emulsion into the tail base of a mouse. 

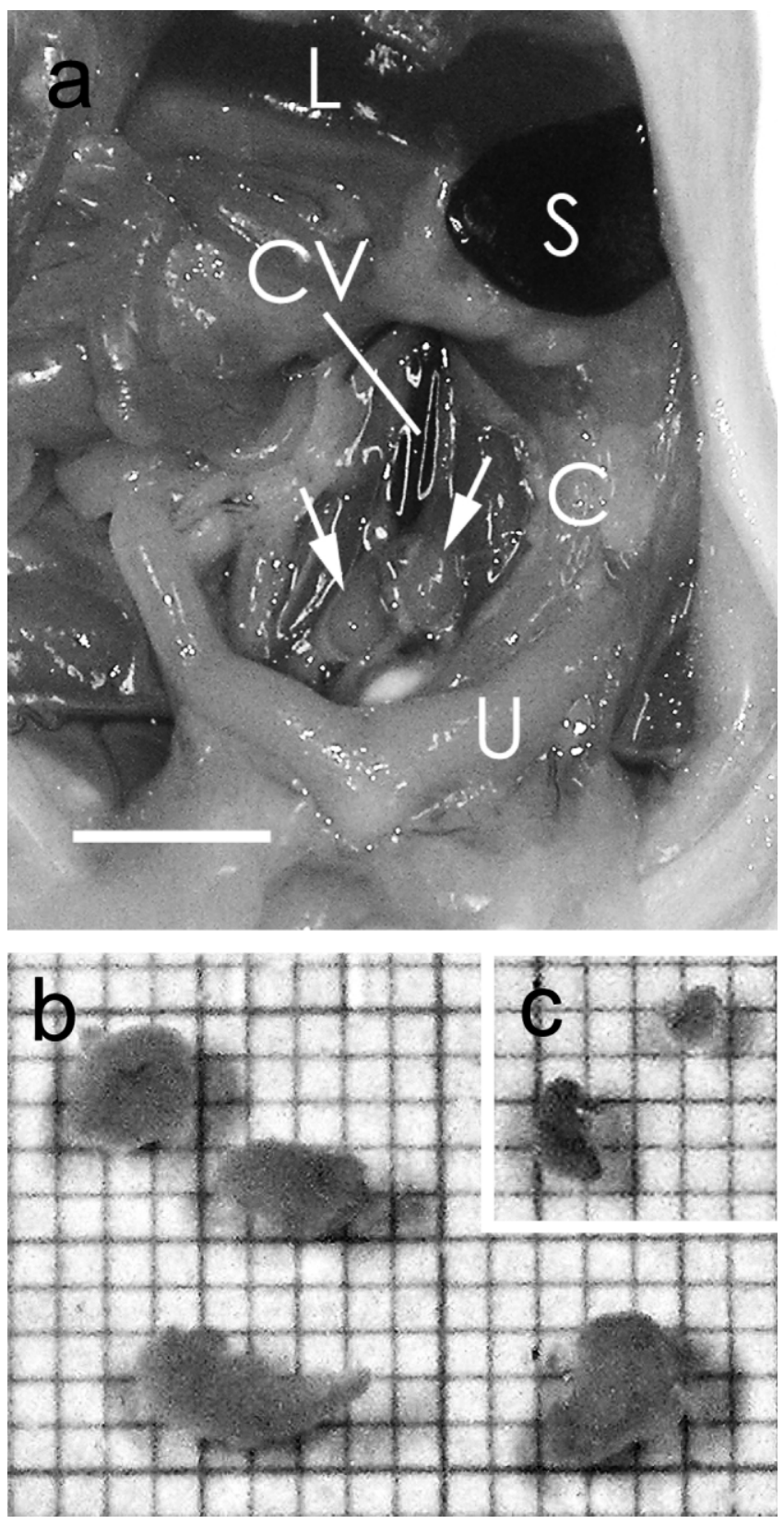

Fig. 2. a: Enlarged iliac lymph nodes (arrows) from a BALB/c mouse injected with antigen emulsion. $\mathrm{C}$, colon; L, liver; S, Spleen; $\mathrm{U}$, uterus; $\mathrm{CV}$, caudal vena cava. $\mathrm{Bar}=5 \mathrm{~mm}$. A small portion of the antigen emulsion was found in the sacral lymph node. b: Enlarged iliac lymph nodes in culture medium from two BALB/c mice 14 days after injection of the antigen emulsion. The scale of the graph paper is $1 \mathrm{~mm}$. c: Normal iliac lymph nodes from an age-matched $\mathrm{BALB} / \mathrm{c}$ mouse.

\section{Serum antibody titers}

The serum antibody titers of mice sacrificed 11, 14, 21, and 28 days after injection were measured (Table 1). Although large individual variations were observed, the median value at day 14 remained low but increased rapidly thereafter, reaching a plateau around day 21 .
Table 1. Titer of antibodies in the serum of immunized mice

\begin{tabular}{lcrrr}
\hline & Day 11 & Day 14 & Day 21 & Day 28 \\
\hline Number of mice & 8 & 8 & 8 & 8 \\
Minimum titer & 40 & 100 & 3200 & 1600 \\
Maximum titer & 640 & 3200 & 25600 & 51200 \\
Median titer & 320 & 1600 & 9600 & 12800 \\
\hline
\end{tabular}

Serum titer was defined as the reciprocal of the highest dilution giving an absorbance reading 0.1 unit greater than the control using ELISA.

$(72)^{(161)}$

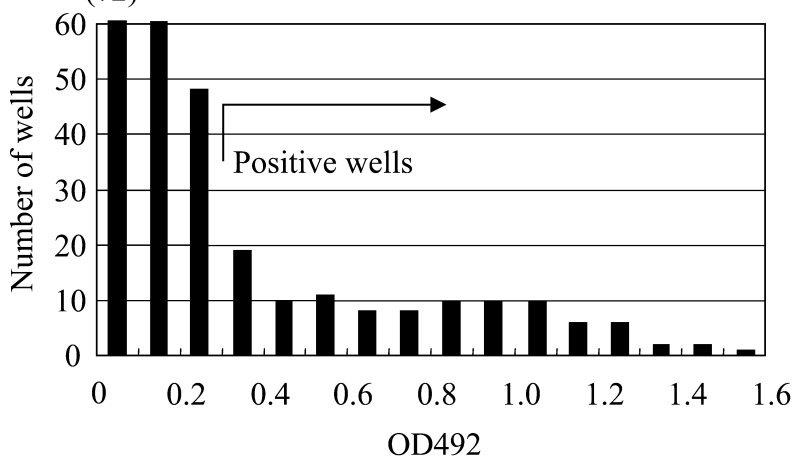

Fig. 3. Histogram of screening results of supernatant for primary hybridomas by ELISA nine days after cell fusion using iliac lymph node lymphocytes from two mice immunized 14 days before. Wells with absorbance of 0.3 units or greater were defined as positive wells, and 103 positive wells were found.

\section{Culture of hybridoma cells}

After cell fusion, the cells were cultured in four 96-well culture plates. Hybridoma colonies were confirmed 4 days after cell fusion. There were several well-grown colonies in each well. Positive wells were detected by ELISA of the culture supernatant at least 9 days after cell fusion. Figure 3 shows a histogram of the results of ELISA screening to detect positive wells following cell fusion using iliac lymph node lymphocytes from mice sacrificed 14 days after immunization with the antigen emulsion.

\section{Timing of fusion}

The number of positive wells was examined using lymphocytes obtained $11,14,21$, and 28 days after injection of the antigen emulsion. Fusion was performed using iliac lymph node lymphocytes from two injected mice. Three independent fusion experiments were performed using lymphocytes from each post-injection time period examined. As shown in Figure 4, a large number of positive wells were obtained using lymphocytes 14 and 21 days after injection. Positive wells were also present using lymphocytes obtained at 11 and 28 days, but at a third of the concentration observed using lymphocytes obtained at 14 and 21 days.

\section{IgM and IgG subclasses}

The production of $\operatorname{IgM}$ and $\operatorname{IgG}$ antibodies was identi- 


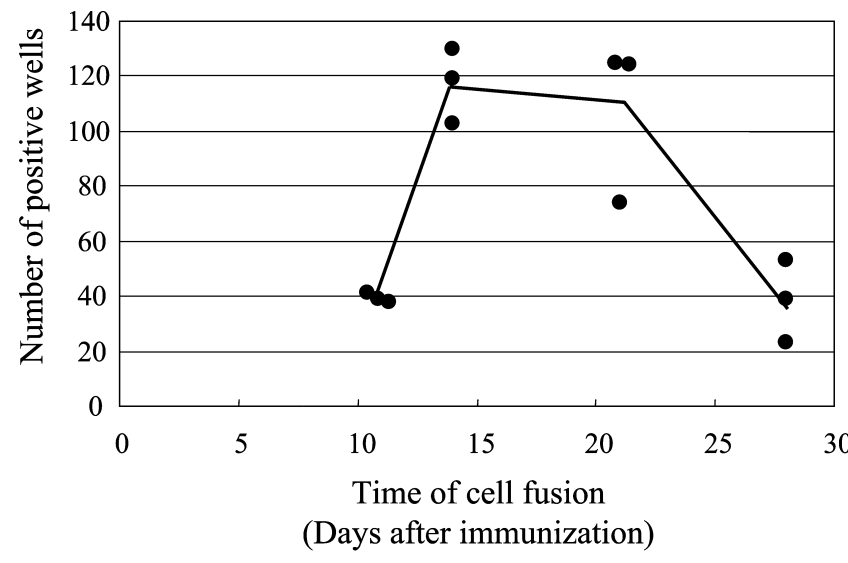

Fig. 4. Timing of cell fusion using the mouse iliac lymph node method. Data points indicate the results of independent experiments, and the line indicates the mean of all the experiments. The differences in the means between days 11 and 14, days 11 and 21, days 14 and 28, and days 21 and 28 were statistically significant.

fied after mouse lymph node lymphocyte fusion (Table 2).

IgG1 was the main subclass observed using lymphocytes obtained 11, 14, 21 and 28 days after injection. This was followed by IgM, which was found in approximately $14 \%$ of positive wells at day 14 , after which levels decreased with time, being present in only $3.4 \%$ of positive wells 28 days after fusion (Table 2). In contrast to the trends demonstrated by $\operatorname{IgM}$ and $\operatorname{IgG} 1$, the relative proportions of $\operatorname{IgG} 2 \mathrm{a}$ and $\mathrm{IgG} 2 \mathrm{~b}$ varied from one fusion experiment to another.
Only $4.0 \%$ to $6.7 \%$ of positive wells produced these subclasses. Only two wells producing IgG3 subclass antibodies were observed in a total of 12 fusion experiments in the present study.

\section{Iliac lymph nodes of C3H/He and ICR mice}

In addition to $\mathrm{BALB} / \mathrm{c}$ mice, $\mathrm{C} 3 \mathrm{H} / \mathrm{He}$ and $\mathrm{ICR}$ mice were injected with the antigen emulsion. As expected, the iliac lymph nodes from these strains of mice enlarged following antigen injection, although more variation in lymph node size on the right and left was observed than in the $\mathrm{BALB} / \mathrm{c}$ mice.

Two attempts at cell fusion were made for each strain using iliac lymph node lymphocytes obtained 16 days after immunization. Forty-four and 111 positive wells were found in $\mathrm{C} 3 \mathrm{H} / \mathrm{He}$ mice, and 92 and 103 in ICR mice, on each attempt. Thus, this method can be used for other strains, in addition to $\mathrm{BALB} / \mathrm{c}$ mice.

\section{Discussion}

The number of positive wells obtained using the present method was 75 to 130 per cell fusion attempt when lymph node lymphocytes were used 14 to 21 days after injection. These numbers are much higher than those obtained in a previous study [5] using the mouse spleen method, which generated 9 to 11 positive wells per cell fusion attempt. In addition, the mouse spleen method requires three immunizations over a four-week immunization period. These results clearly indicate that the use of

Table 2. Relative proportions of IgM and IgG produced by hybridomas using the mouse iliac lymph node method

\begin{tabular}{|c|c|c|c|c|c|c|}
\hline & $\operatorname{IgM}$ & IgG1 & $\operatorname{IgG} 2 \mathrm{a}$ & $\operatorname{IgG} 2 b$ & IgG3 & Total \\
\hline day 11-Exp. 1 & 11 & 27 & 0 & 1 & 0 & 39 \\
\hline day 11-Exp. 2 & 9 & 31 & 0 & 0 & 0 & 40 \\
\hline day 11-Exp. 3 & 8 & 32 & 0 & 0 & 0 & 40 \\
\hline Total & $\begin{array}{c}28 \\
(23.5 \%)\end{array}$ & $\begin{array}{c}90 \\
(75.6 \%)\end{array}$ & $\begin{array}{c}0 \\
(0.0 \%)\end{array}$ & $\begin{array}{c}1 \\
(0.8 \%)\end{array}$ & $\begin{array}{c}0 \\
(0.0 \%)\end{array}$ & $\begin{array}{c}119 \\
(100 \%)\end{array}$ \\
\hline day 14-Exp. 1 & 12 & 92 & 0 & 2 & 0 & 106 \\
\hline day 14-Exp. 2 & 20 & 91 & 11 & 4 & 1 & 127 \\
\hline day 14-Exp. 3 & 20 & 109 & 1 & 7 & 1 & 138 \\
\hline Total & $\begin{array}{c}52 \\
(14.0 \%)\end{array}$ & $\begin{array}{c}292 \\
(78.7 \%)\end{array}$ & $\begin{array}{c}12 \\
(3.2 \%)\end{array}$ & $\begin{array}{c}13 \\
(3.5 \%)\end{array}$ & $\begin{array}{c}2 \\
(0.5 \%)\end{array}$ & $\begin{array}{c}371 \\
(100 \%)\end{array}$ \\
\hline day 21-Exp. 1 & 16 & 101 & 7 & 4 & 0 & 128 \\
\hline day 21-Exp. 2 & 9 & 64 & 2 & 0 & 0 & 75 \\
\hline day 21-Exp. 3 & 6 & 118 & 0 & 0 & 0 & 124 \\
\hline Total & $\begin{array}{c}31 \\
(9.5 \%)\end{array}$ & $\begin{array}{c}283 \\
(86.5 \%)\end{array}$ & $\begin{array}{c}9 \\
(2.8 \%)\end{array}$ & $\begin{array}{c}4 \\
(1.2 \%)\end{array}$ & $\begin{array}{c}0 \\
(0.0 \%)\end{array}$ & $\begin{array}{c}327 \\
(100 \%)\end{array}$ \\
\hline day 28-Exp. 1 & 1 & 18 & 3 & 1 & 0 & 23 \\
\hline day 28-Exp. 2 & 3 & 27 & 13 & 12 & 0 & 55 \\
\hline day 28-Exp. 3 & 0 & 38 & 1 & 0 & 0 & 39 \\
\hline Total & $\begin{array}{c}4 \\
(3.4 \%)\end{array}$ & $\begin{array}{c}83 \\
(70.9 \%)\end{array}$ & $\begin{array}{c}17 \\
(14.5 \%)\end{array}$ & $\begin{array}{c}13 \\
(11.1 \%)\end{array}$ & $\begin{array}{c}0 \\
(0.0 \%)\end{array}$ & $\begin{array}{c}117 \\
(100 \%)\end{array}$ \\
\hline
\end{tabular}


enlarged iliac lymph node lymphocytes from mice injected intramuscularly with an antigen emulsion via tail base is an excellent method by which to prepare hybridomas producing mouse monoclonal antibodies. We named this method the "mouse iliac lymph node method" or more simply, the "mouse lymph node method". It has several advantages. Specifically, only one antigen injection is required and lymph nodes can be used from approximately two weeks after injection. Lymph node lymphocytes from two mice are sufficient for a single fusion attempt, and a high yield of positive wells is obtained. This method saves time, effort, antigen requirements, expense, and has a better chance of success.

It has been 30 years since the first report by Köhler and Milstein of monoclonal antibodies appeared in Nature [7]. However, the present study is the first to describe monoclonal antibody production using a mouse iliac lymph node method. The major reason for this delay has been the small size of mouse lymph nodes, which necessitates 5 or more mice to be injected for immunization for a single cell fusion $[2,8,9]$. Another reason is that high antibody titers in serum have been thought to indicate the potential for success of cell fusion, and high titers are achieved with the mouse spleen method. This generally requires two or three booster injections, requiring at least four weeks from the time of initial injection. This long period of immunization might in fact reduce the number of positive wells obtained and make it difficult to achieve the success of the present mouse lymph node method.

A particular stage of $\mathrm{B}$ cell differentiation is thought to be most suitable for cell fusion in order to produce antibodysecreting hybridomas $[1,4,12]$. In the conventional mouse spleen method [12], the last booster injection is usually made intravenously with antigen in saline 3 or 4 days before cell fusion to induce the splenic lymphocytes into a suitable stage for cell fusion [12]. Using the present mouse iliac lymph node method, the greatest number of positive wells was observed using lymphocytes obtained 14 to 21 days after injection, and decreased numbers were observed using lymphocytes obtained 28 days after injection. Since the iliac lymph nodes were similar in size 14 and 28 days after injection, and since similar numbers of hybridomas were observed in each well from one fusion attempt to the next, the observed decrease at day 28 in the proportion of positive wells may have been due to a shift of B cells into an unsuitable stage.

Hybridomas produced using the mouse lymph node method primarily produced IgG1 antibodies (approximately $80 \%$ of total antibody production), but $\operatorname{IgM}, \operatorname{IgG} 2 \mathrm{a}$ and IgG2b antibodies were also obtained. IgM was easily obtained when mouse lymph nodes were used two weeks after injection. Individual mouse differences were observed with regard to the production of $\mathrm{IgG} 2 \mathrm{a}$ and $\mathrm{IgG} 2 \mathrm{~b}$; however, these subclasses were obtained after several attempts at cell fusion.

Mirza et al. [8] reported in 1987 that immunization by injection of antigen into the hind footpads of mice with sub- sequent fusion of lymphocytes from popliteal and inguinal lymph nodes produced more antibody-secreting hybridomas than either intradermal immunization and lymph node lymphocyte fusion or conventional subcutaneous immunization with intraperitoneal booster injections followed by splenic lymphocyte fusion. However, this method remains unpopular since lymph node lymphocytes from five mice are required for a single fusion attempt. Moreover, lymph node enlargement is less successful than with the current method. We tried to immunize mice in the same way as Mirza et al. [8] but found it impossible to inject $50 \mu \mathrm{l}$ of antigen emulsion into a footpad without leakage. At most, we were able to inject $15 \mu \mathrm{l}$ of the emulsion. Of note, the injection site became less obvious several days after injection (unpublished data). In contrast, intramuscular tail base injection of $50 \mu \mathrm{l}$ of emulsion was easy, and the injected emulsion was still evident in the intramuscular space 28 days after injection.

Davis et al. [3] produced monoclonal antibodies following a single fusion attempt using a mixture of lymphocytes from inguinal and iliac lymph nodes from 10 mice. Although they used iliac lymph node lymphocytes as the source of B lymphocytes for the first time, their method is clearly different from the present mouse lymph node method. They injected the mice subcutaneously, not intramuscularly, at the tail base four times at two-week intervals, and used both inguinal and iliac lymph nodes. Judging from the results of subcutaneous injection in the present study, subcutaneous injection at the tail base of a mouse induces hypertrophy of inguinal lymph nodes, although enlargement of both inguinal and iliac lymph nodes occasionally occurs. The main target lymph nodes in the Davis et al. study were thought to be the inguinal lymph nodes. They established 43 antibody clones; however, these results were similar to those obtained following three fusion attempts using splenic lymphocytes from mice after administration of a similar schedule of intraperitoneal injections [3]. As such, they did not feel there was any great advantage to using lymph node lymphocytes as the source of B lymphocytes.

The effect of booster injections was not examined in the present study, because booster injections given three or four days prior to sacrifice did not influence the number of positive wells obtained using the rat lymph node method in a previous study [5]. Typically, booster injections are given at least one week after initial immunization, which would lengthen the immunization period required for this experiment and increase the amount of antigen required. The antigen saved could then be used to immunize more mice.

We have previously reported on a rat lymph node method [5]. This method uses lymphocytes obtained from enlarged medial iliac lymph nodes following hind footpad immunization for cell fusion. Intramuscular tail base injection of antigen into rats to obtain lymphocytes for cell fusion was also examined in the present study, and tail base injection was observed to produce enlarged rat medial iliac lymph nodes, from which lymphocytes for cell fusion were 
obtained and a number of hybridomas detected by ELISA (unpublished data). Therefore, the present study is the first report indicating that the iliac lymph node method is also useful in rats. The tail base is a more humane site for immunization than the hind footpads. Thus, researchers should use the tail base for immunization when using the rat lymph node method to achieve monoclonal antibody production using lymphocytes from enlarged medial iliac lymph nodes.

Given the immunotolerance of rats to various rat antigens, monoclonal mouse antibodies have an important role in research. Rabbit monoclonal antibodies are commercially available from Knight's group [11]; however, a number of researchers are interested in producing their own rodent monoclonal antibodies. Although this data has not been published, we were able to produce antibodies to a rat antigen using the mouse lymph node method. We produced more than 30 clones of antibodies against rat renal basement membrane collagen, otherwise known as type IV collagen [6]. For this we used a soluble fraction purified from rat solubilized renal basement membrane as the antigen [6]. We established approximately 10 clones each of $\operatorname{IgG} 1$, IgG2a, and $\operatorname{IgG} 2 \mathrm{~b}$, all of which were strongly reactive with native rat renal basement membrane, as demonstrated by indirect immunofluorescence. This required four cell fusion attempts since only approximately $10 \%$ of the positive wells contained $\mathrm{IgG} 2 \mathrm{a}$ and $\mathrm{IgG} 2 \mathrm{~b}$ antibodies, while the rest contained IgG1. This clearly indicates that the mouse lymph node method is a reliable technique.

\section{Acknowledgments}

We would like to thank Dr. Fumihiro Shigei, Chairman of the Board, for financial support, and Dr. Masafumi Taki, Director of the Shigei Medical Research Hospital, as well as Dr. Yoshifumi Ninomiya, professor of Okayama University Medical School, for their helpful advice. We would also like to thank Mrs. Chieko Takahashi for assistance with animal husbandry.

\section{References}

1. Andersson, J. and Melchers, F. (1978) The antibody repertoire of hybrid cell lines obtained by fusion of X63-AG8 myeloma cells with mitogen-activated B-cell blasts. Curr. Top. Microbiol. Immunol. 81; 130-139.

2. Campbell, A. M. (1984) Monoclonal antibody technology. The production and characterization of rodent and human hybridomas. In "Laboratory Techniques in Biochemistry and Molecular Biology”, Vol. 13, ed. by R. H. Burdon and P. H. van Knippenberg, Elsevier Science Publishers, Amsterdam.

3. Davis, C. G., Gallo, M. L. and Corvalan, J. R. (1999) Transgenic mice as a source of fully human antibodies for the treatment of cancer. Cancer Metastasis Rev. 18; 421-425.

4. Goding, J. W. (1980) Antibody production by hybridomas. J. Immunol. Methods 39; 285-308.

5. Kishiro, Y., Kagawa, M., Naito, I. and Sado, Y. (1995) A novel method of preparing rat-monoclonal antibody-producing hybridomas by using rat medial iliac lymph node cells. Cell Struct. Funct. 20; 151-156.

6. Kohda, T., Okada, S., Hayashi, A., Kanzaki, S., Ninomiya, Y., Taki, M. and Sado, Y. (2004) High nephritogenicity of monoclonal antibodies belonging to $\operatorname{IgG} 2 \mathrm{a}$ and $\mathrm{IgG} 2 \mathrm{~b}$ subclasses in rat anti-GBM nephritis. Kidney Int. 66; 177-186.

7. Köhler, G. and Milstein, C. (1975) Continuous cultures of fused cells secreting antibody of predefined specificity. Nature 256; 495-497.

8. Mirza, I. H., Wilkin, T. J., Cantarini, M. and Moore, K. (1987) A comparison of spleen and lymph node cells as fusion partners for the raising of monoclonal antibodies after different routes of immunisation. J. Immunol. Methods 105; 235-243.

9. Reeves, J. P. and Reeves, P. A. (1994) Selected surgical procedures. Removal of lymphoid organs. In "Current Protocols in Immunology" ed. by J. E. Coligan, A. M. Kruisbeek, D. H. Margulies, E. M. Shevach and W. Strober, John Wiley \& Sons, New York, pp. 1.9.1-1.9.3.

10. Shulman, M., Wilde, C. D. and Köhler, G. (1978) A better cell line for making hybridomas secreting specific antibodies. Nature 276; 269-270.

11. Spieker-Polet, H., Sethupathi, P., Yam, P. C. and Knight, K. L. (1995) Rabbit monoclonal antibodies: generating a fusion partner to produce rabbit-rabbit hybridomas. Proc. Natl. Acad. Sci. US A 92; 9348-9352.

12. Stähli, C., Staehelin, T., Miggiano, V., Schmidt, J. and Haring, P. (1980) High frequencies of antigen-specific hybridomas: dependence on immunization parameters and prediction by spleen cell analysis. J. Immunol. Methods 32; 297-304. 